\title{
Association between maternal smoking during pregnancy and risk of bone fractures in offspring: a systematic review and meta-analysis
}

\author{
Erfan Ayubi, $\mathrm{PhD}^{1,2}$, Saeid Safiri, $\mathrm{PhD}^{3,4}$, Kamyar Mansori, $\mathrm{PhD}^{5 *}$ \\ ${ }^{1}$ Health Promotion Research Center, ${ }^{2}$ Department of Community Medicine, School of Medicine, Zahedan University of Medical Sciences, Zahedan, Iran; ${ }^{3}$ Aging \\ Research Institute, ${ }^{4}$ Department of Community Medicine, School of Medicine, Tabriz University of Medical Sciences, Tabriz, Iran; ${ }^{5}$ Department of Biostatistics and \\ Epidemiology, School of Medicine, Zanjan University of Medical Sciences, Zanjan, Iran
}

This study aimed to investigate the effect of maternal smoking during pregnancy (MSDP) on the risk of bone fractures in the offspring through a systematic review and meta-analysis. The PubMed, Web of Science, and Scopus databases were systematically searched for relevant articles published through July 2019. According to heterogeneity, the pooled risk ratio (RR) and odds ratio (OR) and their corresponding 95\% confidence interval $(\mathrm{CI})$ were obtained using fixed or random effects models. The heterogeneity and quality of the included studies were assessed by the I-squared $\left(\mathrm{I}^{2}\right)$ statistic and the NewcastleOttawa scale, respectively. Sensitivity analyses were performed to test the effect of MSDP misclassification on the results. The review of 842 search records yielded 5 studies including 8,746 mother-child pairs that were included in the meta-analysis. Pooling adjusted effect measures showed that MSDP was not associated with a later risk of bone fractures in the offspring (pooled RR, 1.15; 95\% CI, 0.84-1.58; $\mathrm{I}^{2}=66.8 \%$; $P=0.049$ ). After the adjustment for misclassification, MSDP may be associated with a $27 \%$ increased risk of bone fracture (pooled OR, $\left.1.27 ; 95 \% \mathrm{CI}, 1.00-1.62 ; \mathrm{I}^{2}=0 \% ; P=0.537\right)$. After the adjustment for misclassification, MSDP is associated with an increased risk of bone fractures among children whose mothers smoked during pregnancy.

Key words: Maternal smoking, Meta analyses, Misclassification, Pregnancy, Bone fractures

\section{Key message}

Question: What is the effect of maternal smoking during preg. nancy (MSDP) on the risk of bone fractures in the offspring?

Finding: After the adjustment for misclassification, MSDP may be associated with a $27 \%$ increased risk of bone fracture in the offspring (pooled odds ratio, 1.27; 95\% confidence interval, $\left.1.00-1.62 ; \mathrm{I}^{2}=0 \% ; P=0.537\right)$.
Meaning: Preventive measures and health education programs should be designed and implemented to encourage women to stop smoking, especially during.

\section{Introduction}

Bone fracture is one of the most common injuries in children. An estimated 27\%-50\% of children suffer from bone fractures before 18 years of age. ${ }^{1,2)}$ It has been suggested that even children without a history of bone diseases may experience frequent fractures in childhood and adolescence. ${ }^{2)}$ Unbiased and larger epidemiological studies are required to confirm the factors associated with bone fracture occurrence in children and youth. Studies of the etiology of bone fractures suggest that some characteristics of children ${ }^{3-10)}$ and parents ${ }^{11-15)}$ may be associated with an increased risk of bone fractures in children and youth.

Maternal smoking during pregnancy (MSDP) is one of the parental characteristics that was recently suggested as a risk factor of bone fractures in offspring; ${ }^{12)}$ however, its role as a risk factor was not confirmed in all studies. For example, it was a risk factor in one study ${ }^{16}$ ) but a nonsignificant negative factor between 2 aforementioned factors in another study. ${ }^{17)}$ Evidence of the association between MSDP bone fractures in offspring was primarily derived from observational studies, which are prone to many possible sources of bias. The results of studies concerning the association between MSDP and bone fractures may be prone to recall bias. In other words, smoking during pregnancy is recalled by mothers after having given birth ${ }^{17)}$ or even later, ${ }^{2)}$ and mothers of children with bone fractures are likely to remember smoking during pregnancy differently than mothers of fracturefree controls.

Considering the above issues, the present study aimed to systemically review and meta-analyze potential studies concerning the association between MSDP and bone fractures in offspring

\footnotetext{
Corresponding author: Kamyar Mansori, PhD. Department of Biostatistics and Epidemiology, School of Medicine, Zanjan University of Medical Sciences, Karmandan Town, Haj Ahmad Mahdavi Street, Zanjan, Iran

凶E-mail: kamyarmansori@yahoo.com, https://orcid.org/0000-0003-3527-4741

Received: 25 November, 2019, Revised: 18 January, 2020, Accepted: 31 January, 2020

This is an open-access article distributed under the terms of the Creative Commons Attribution Non-Commercial License (http://creativecommons.org/licenses/bync/4.0/) which permits unrestricted non-commercial use, distribution, and reproduction in any medium, provided the original work is properly cited.

Copyright (c) 2020 by The Korean Pediatric Society
} 


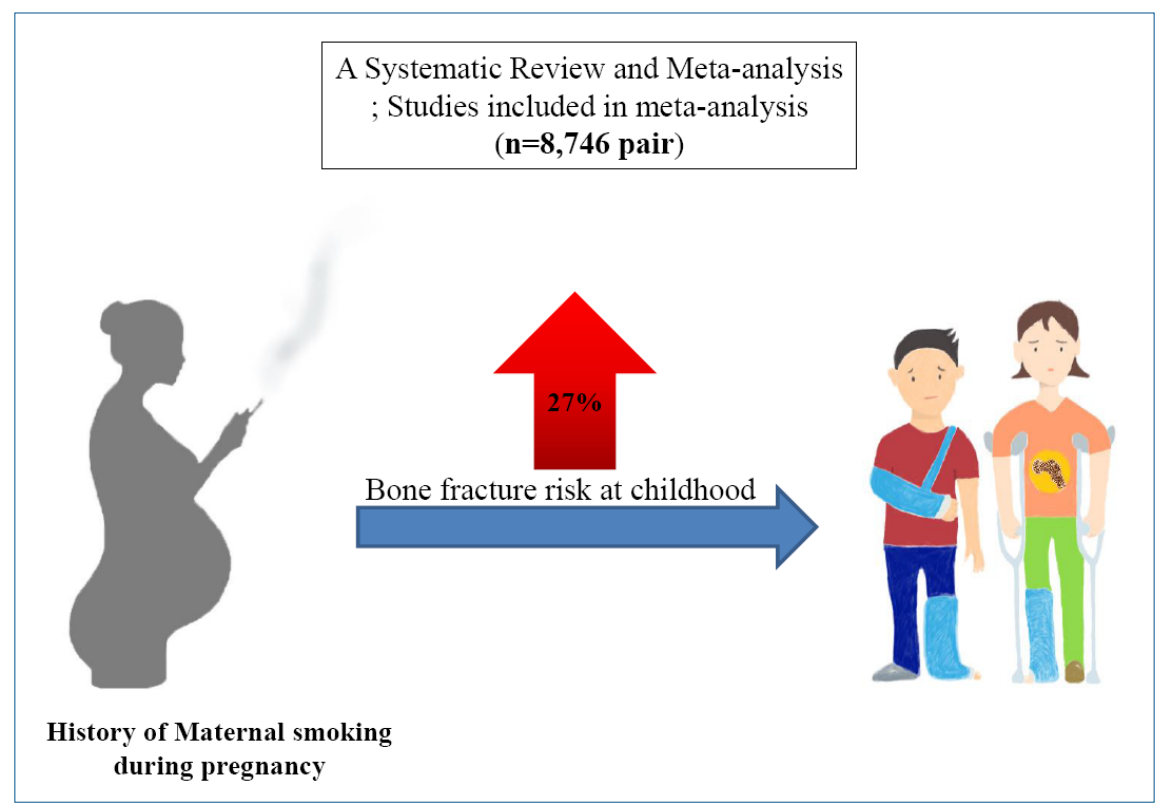

Graphical abstract. The effect of maternal smoking during pregnancy (MSDP) on the risk of bone fractures in offspring after the adjustment for MSDP misclassification

and adjust for the effect of MSDP misclassification on the results.

\section{Methods}

This systematic review and meta-analysis was performed according to the Preferred Reporting Items for Systematic Reviews and Meta-Analyses statement. ${ }^{18)}$

\section{Search strategy}

The PubMed, Scopus, and Web of Sciences databases were searched up to July 2019 . The search strategy was developed by combining keywords including "bone fractures and maternal smoking and pregnancy and children." The details of the search strategy for each database are presented in Supplementary material 1. Moreover, the reference lists of the included articles were also manually screened to identify relevant studies that the search strategy failed to retrieve.

\section{Study selection}

Studies identified in the initial search were imported into bibliographic citation management software (Endnote X6; Clarivate Analytics, Philadelphia, PA, USA) for screening and duplicate checking. After duplications were discarded, the titles and abstracts of the identified studies were reviewed independently by 2 authors (EA and KM). In cases of disagreement, the 2 authors discussed the article and reached consensus.

\section{Eligibility criteria}

In the next stage, the full texts of eligible original studies were reviewed to obtain more details. All original observational studies that evaluated the association between MSDP and bone fracture in the offspring and met following criteria were considered for this systematic review and meta-analysis: observational studies that reported relative measures and confidence intervals (CIs); and provided crude data for estimating the aforementioned association. Animal and lab studies, case reports, reviews, meeting abstracts, correspondence, and editorials were excluded.

\section{Data extraction}

The data extraction was performed by 2 independent authors (EA and $\mathrm{KM}$ ) using a standard form in Excel software and included the following: first author, year of publication, country, study design, age and sex of children who experienced bone fractures, sample size, number of bone fracture cases, diagnostic methods of MSDP and bone fractures, type of relative measures ( $95 \% \mathrm{CI})$, and adjusted covariates.

The quality assessment was performed using the NewcastleOttawa Scale (NOS). ${ }^{19)}$ This scale criticized cohort and case control studies according to 3 domains including study group selection (4 items), study group comparability ( 2 items), and exposure and outcome measurements ( 3 items); those who received a NOS score of at least 6 were considered of high quality. Notably, only one author (KM) conducted a quality assessment of the included studies.

\section{Statistical analysis}

The relative measures were risk ratio $(\mathrm{RR})$ and odds ratio $(\mathrm{OR})$ with 95\% CI. Heterogeneity among the included studies was assessed using the $\mathrm{I}^{2}$ statistic and Cochran $\mathrm{Q}$ test, on which values higher than $50 \%$ and $P<0.05$ imply substantial heterogeneity. ${ }^{20)}$ Regardless of interstudy heterogeneity, the pooled relative measure were calculated using both a fixed effect model (inverse variance) and a random effects model (I-V heterogeneity) to assess the impact of small study effects on the results. No attempt was made to assess potential publication bias when fewer than 
10 studies were included. ${ }^{21)}$ Values of $P<0.05$ were considered significant.

\section{Sensitivity analysis}

In the included studies, information about MSDP were gathered based on mothers' recall; thus, the information may be subject to misclassification bias. In other words, mothers may report smoking without actual exposure or vice versa, the sensitivity and specificity of recall is less than $100 \%$. Here we used a Bayesian bias model to test the effect of the potential MSDP misclassification on the results. The details of the sensitivity analysis using the Bayesian model are presented in Supplementary material 2 .

\section{Results}

\section{Study characteristics}

Fig. 1 shows the Preferred Reporting Items for Systematic Reviews and Meta-Analyses flow diagram of the review process. The initial search identified 842 articles. After the removal of duplicates using Endnote X6 $(n=43)$, the titles and abstracts of 799 articles were screened and 7 eligible articles were ultimately identified. ${ }^{12,16,17,22-25)}$ The full-text review of those 7 articles revealed that 3 did not meet the eligibility criteria. ${ }^{12,22,25)}$ Review of the reference lists of the eligible articles identified another article; ; $^{2}$ finally, 5 articles ${ }^{2,16,17,23,24)}$ were included in the systematic review and meta-analysis.

Table 1 displays the characteristics of the included studies. The included studies were conducted in Australia (2 studies), ${ }^{17,24)}$ the
UK (1 study), ${ }^{2)}$ New Zealand (1 study), and Finland (1 study). ${ }^{16}$ ) Most of the included studies $(n=4)$ used a cohort study design that involved a total of 8,596 children, including 901 with at least one bone fracture before age $18 .^{16,17,23,24)}$ The other included study had a case control design ${ }^{2}$ and involved 100 cases and 50 controls. Boys more often suffered from fractures than girls. In all included studies, the ascertainment of smoking during pregnancy was based on mothers' recall.

\section{Quality of included studies}

Table 2 shows results of the risk of bias assessment using the Newcastle-Ottawa Scale (NOS). According to the NOS, all of the included studies received a score $\geq 6$ except for the study by Jones et al., ${ }^{17)}$ which had a NOS score of 5 .

\section{Effect of MSDP on bone fracture}

Figs. 2-4 show the results of the fixed and random effects meta-analysis of the association between MSDP and bone fractures. According to the fixed effect model, the overall crude OR (95\% CI) was 1.40 (1.06-1.85), $\mathrm{I}^{2}=5.8 \%, P=0.364$ (Fig. 2). According to the random effects model, the overall adjusted RR (95\% CI) of the risk of bone fractures in children whose mothers smoked during pregnancy was 1.15 (0.84-1.58), $\mathrm{I}^{2}=$ 66.8\%, $P=0.049$ (Fig. 3). In 2 approaches (deterministic and probabilistic), the fixed effect meta-analysis of overall OR after the correction for misclassification shows that MSDP increases the odds of bone fractures by $27 \%\left(\mathrm{I}^{2}=0.0 \%, P=0.537, \mathrm{I}^{2}=\right.$ $0.0 \%, P=0.548$, respectively) (Fig. 4).

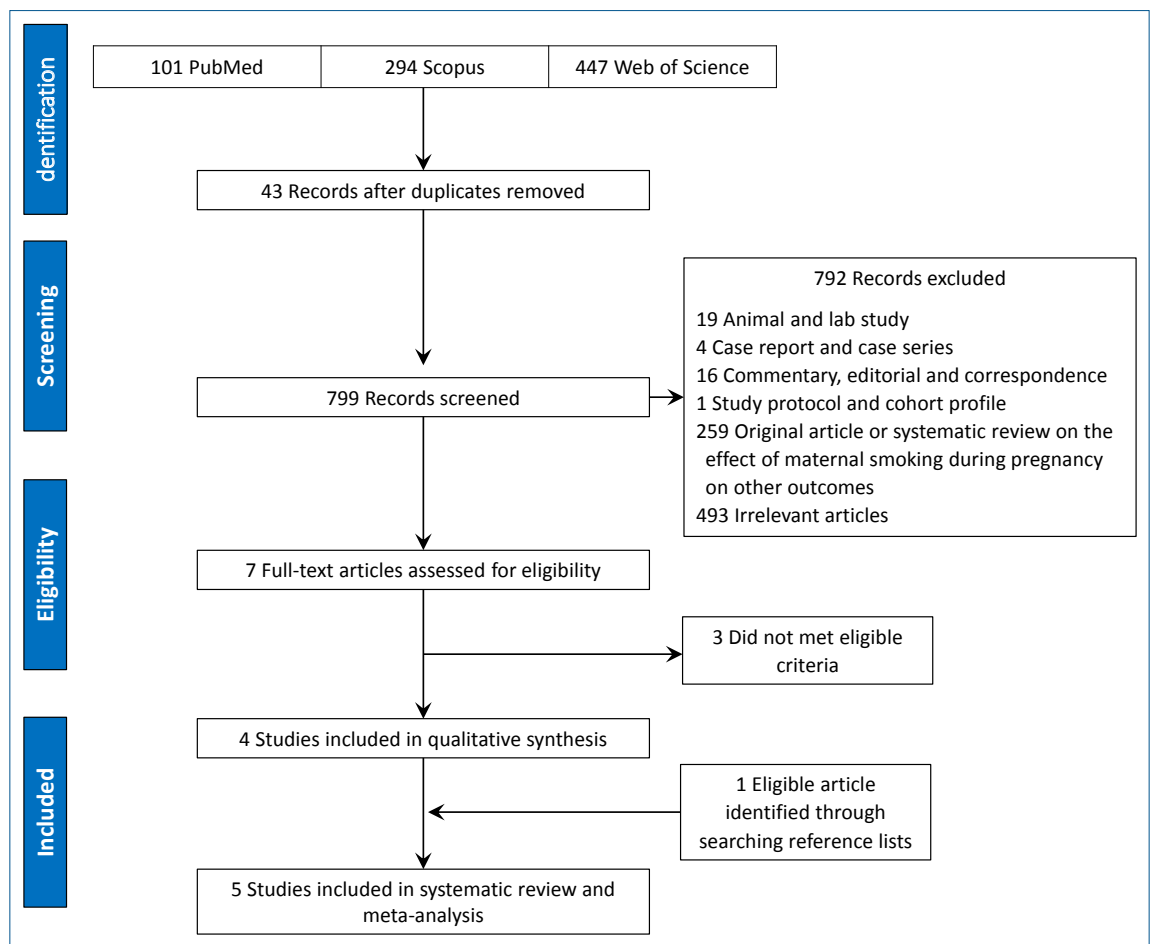

Fig. 1. Preferred Reporting Items for Systematic Reviews and Meta-Analyses flow diagram of the study selection process for a systematic review and meta-analysis of the association between maternal smoking during pregnancy and the risk of fractures. 
Table 1. Characteristics of the included studies

\begin{tabular}{|c|c|c|c|c|c|c|c|c|c|}
\hline Study & $\begin{array}{c}\text { Year of } \\
\text { publication }\end{array}$ & Country & $\begin{array}{l}\text { Study } \\
\text { design }\end{array}$ & $\begin{array}{l}\text { Total cases/ } \\
\text { sample size }\end{array}$ & $\begin{array}{l}\text { boy with } \\
\text { bone } \\
\text { fractures } \\
(\%)\end{array}$ & $\begin{array}{l}\text { Age }(y r) \\
\text { of bone } \\
\text { fractures } \\
\text { cases } \\
\text { (mean } \pm S D)\end{array}$ & $\begin{array}{l}\text { Ascertainment } \\
\text { smoking during } \\
\text { pregnancy }\end{array}$ & $\begin{array}{l}\text { Ascertainment of } \\
\text { bone fractures }\end{array}$ & Confounders \\
\hline $\begin{array}{l}\text { Jones et } \\
\text { al. }{ }^{17)}\end{array}$ & 2013 & Australia & Cohort & $159 / 415$ & - & $10.4 \pm 4$ & $\begin{array}{l}\text { Mothers' recall when } \\
\text { children's birth }\end{array}$ & $\begin{array}{l}\text { Parent reports con- } \\
\text { firmed by medical } \\
\text { records }\end{array}$ & $\begin{array}{l}\text { Current height, weight, } \\
\text { age, sex and breast- } \\
\text { feeding }\end{array}$ \\
\hline $\begin{array}{l}\text { Jones et } \\
\text { al. }{ }^{23)}\end{array}$ & 2004 & $\begin{array}{l}\text { New } \\
\text { Zealand }\end{array}$ & Cohort & $622 / 1,139$ & 63.2 & $\begin{array}{l}\text { Range, } \\
3-18\end{array}$ & $\begin{array}{l}\text { Mothers' recall when } \\
\text { children were aged } \\
9 \text { years }\end{array}$ & Parent reports & Sex and age \\
\hline $\begin{array}{l}\text { Parviainen } \\
\text { et al. }^{16)}\end{array}$ & 2017 & Finland & Cohort & $88 / 6,718$ & 63.6 & $4.1 \pm 1.86$ & $\begin{array}{l}\text { Mothers' recall when } \\
\text { children's birth }\end{array}$ & Medical records & $\begin{array}{l}\text { Child's sex, childhood } \\
\text { rheumatism, asthma, } \\
\text { BMl of the child, so- } \\
\text { cioeconomic status } \\
\text { of the family and ma- } \\
\text { ternal age }\end{array}$ \\
\hline $\begin{array}{l}\text { Ma and } \\
\text { Jones }^{24)}\end{array}$ & 2002 & Australia & Cohort & $32 / 324$ & 72 & $8.32 \pm 0.34$ & $\begin{array}{l}\text { Mothers' recall when } \\
\text { children were aged } \\
8 \text { years }\end{array}$ & $\begin{array}{l}\text { Parent reports con- } \\
\text { firmed by X-ray }\end{array}$ & - \\
\hline $\begin{array}{l}\text { Manias et } \\
{\text { al. }{ }^{2)}}^{2}\end{array}$ & 2006 & UK & $\begin{array}{l}\text { Case } \\
\text { control }\end{array}$ & $100 / 150$ & 51 & $9.57 \pm 3.17$ & Mothers' recall & $\begin{array}{l}\text { Parent reports con- } \\
\text { firmed by medical } \\
\text { records }\end{array}$ & - \\
\hline
\end{tabular}

deviation; BMI, body mass index.

Table 2. Results of the risk of bias assessment using the Newcastle-Ottawa Scale (NOS)

\begin{tabular}{|c|c|c|c|c|c|c|c|c|c|c|c|c|c|c|c|c|c|c|}
\hline \multirow{3}{*}{ Author (yr) } & \multirow[b]{2}{*}{ Study design } & \multicolumn{8}{|c|}{ Item for cohort study } & & & & & & & & & \multirow{2}{*}{$\begin{array}{l}\text { Total } \\
\text { NOS } \\
\text { star }\end{array}$} \\
\hline & & \multicolumn{4}{|c|}{ Selection } & \multirow[b]{2}{*}{ 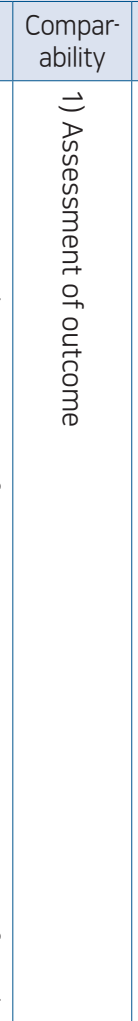 } & \multicolumn{3}{|c|}{ Outcome } & \multicolumn{4}{|c|}{ Selection } & \multicolumn{4}{|c|}{$\begin{array}{c}\text { Compar- } \\
\text { ability }\end{array}$ Exposure } & \\
\hline & & 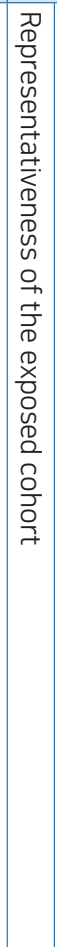 & 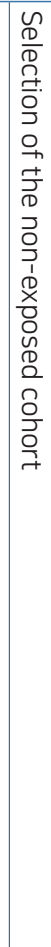 & 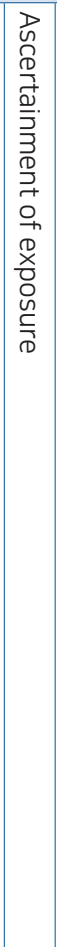 & 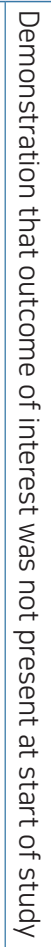 & & 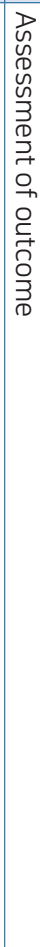 & 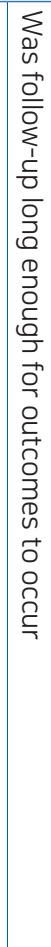 & 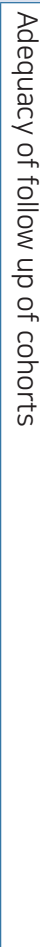 & 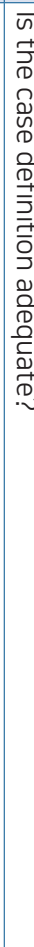 & 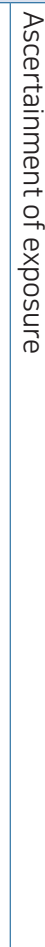 & 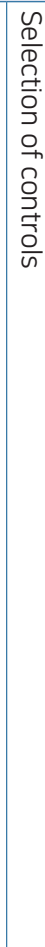 & 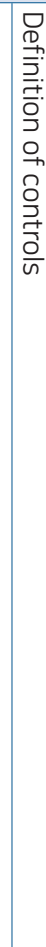 & 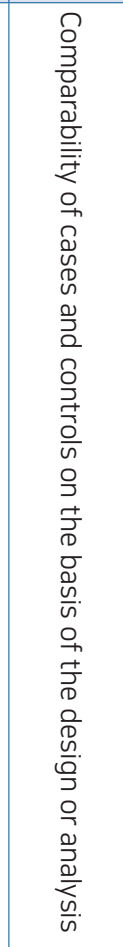 & 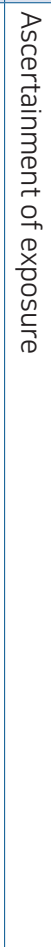 & 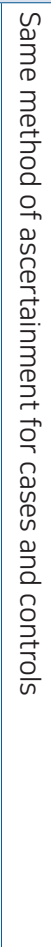 & 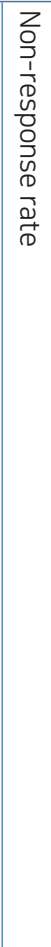 & \\
\hline $\begin{array}{l}\text { Jones et al. }(2013)^{17)} \\
\text { Jones et al. }(2004)^{23)} \\
\text { Parviainen et al. }(2017)^{16)} \\
\text { Ma and Jones }(2002)^{24)} \\
\text { Manias et al. }(2006)^{2)}\end{array}$ & $\begin{array}{c}\text { Cohort } \\
\text { Cohort } \\
\text { Cohort } \\
\text { Cohort } \\
\text { Case-control }\end{array}$ & * & $\begin{array}{l}* \\
* \\
*\end{array}$ & $\begin{array}{l}* \\
* \\
* \\
*\end{array}$ & $\begin{array}{l}* \\
* \\
* \\
*\end{array}$ & $\begin{array}{l}* \\
* \\
* \\
*\end{array}$ & * & $\begin{array}{l}* \\
* \\
* \\
*\end{array}$ & * & * & $*$ & * & * & ** & $*$ & * & & $\begin{array}{c}* * * * * \\
* * * * * * * * \\
* * * * * * * \\
* * * * * * \\
* * * * * * * *\end{array}$ \\
\hline
\end{tabular}




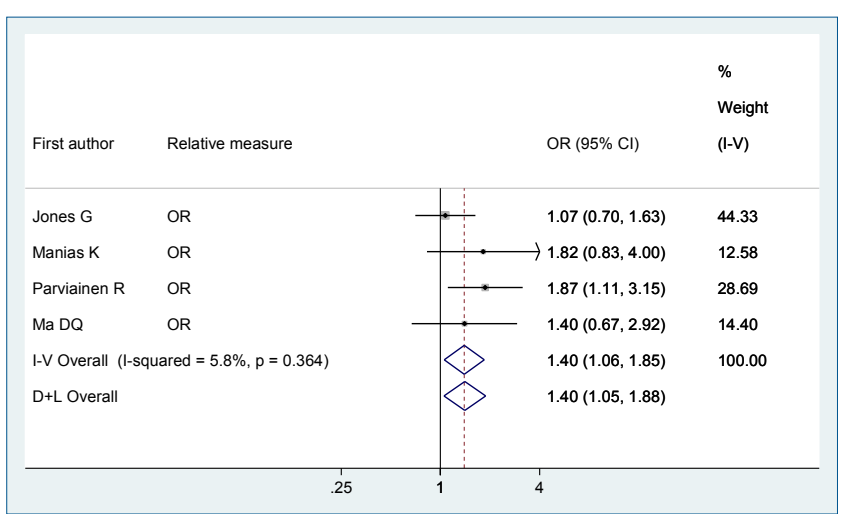

Fig. 2. Forest plot of 4 studies showing the crude effect of maternal smoking during pregnancy on the risk of bone fractures in offspring through a fixed effect model. $\mathrm{Cl}$, confidence interval; $\mathrm{D}+\mathrm{L}$, DerSimonian and Laird; I-V, inverse variance; OR, odds ratio.

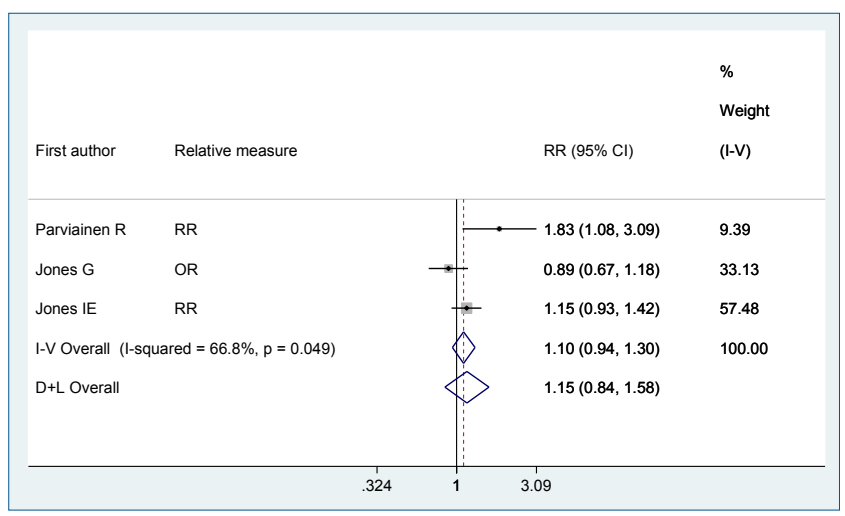

Fig. 3. Forest plot of 3 studies showing the adjusted effect of maternal smoking during pregnancy on the risk of bone fractures in offspring through a random effects model. $C l$, confidence interval; $D+L$, DerSimonian and Laird; I-V, inverse variance; OR, odds ratio; RR: risk ratio.

\section{Discussion}

This study aimed to determine the association between MSDP and risk of bone fractures in offspring using a systematic review and meta-analysis. The results demonstrated that MSDP is associated with an increased risk of bone fractures; i.e., children whose mothers smoke during pregnancy are $15 \%$ more likely to suffer from bone fractures than children whose mothers do not smoke during pregnancy (overall RR, 1.15; 95\% CI, 0.841.58); however, this increased risk was not statistically significant. However, after the correction for MSDP misclassification, we observed a significant association between MSDP and bone fractures; thus, MSDP may be associated with a 1.27 -fold increased risk of bone fractures among children of smoking mothers (overall RR, 1.27; 95\% CI, 1.00-1.62; $\mathrm{I}^{2}=0 \% ; P=$ 0.537). The findings of studies concerning the association between MSDP and the risk of bone fractures in offspring are conflicting.

The inconsistency noted across the included studies may have been due to several reasons. First, although the resulting effect measures tended to shrink toward null after the correction of

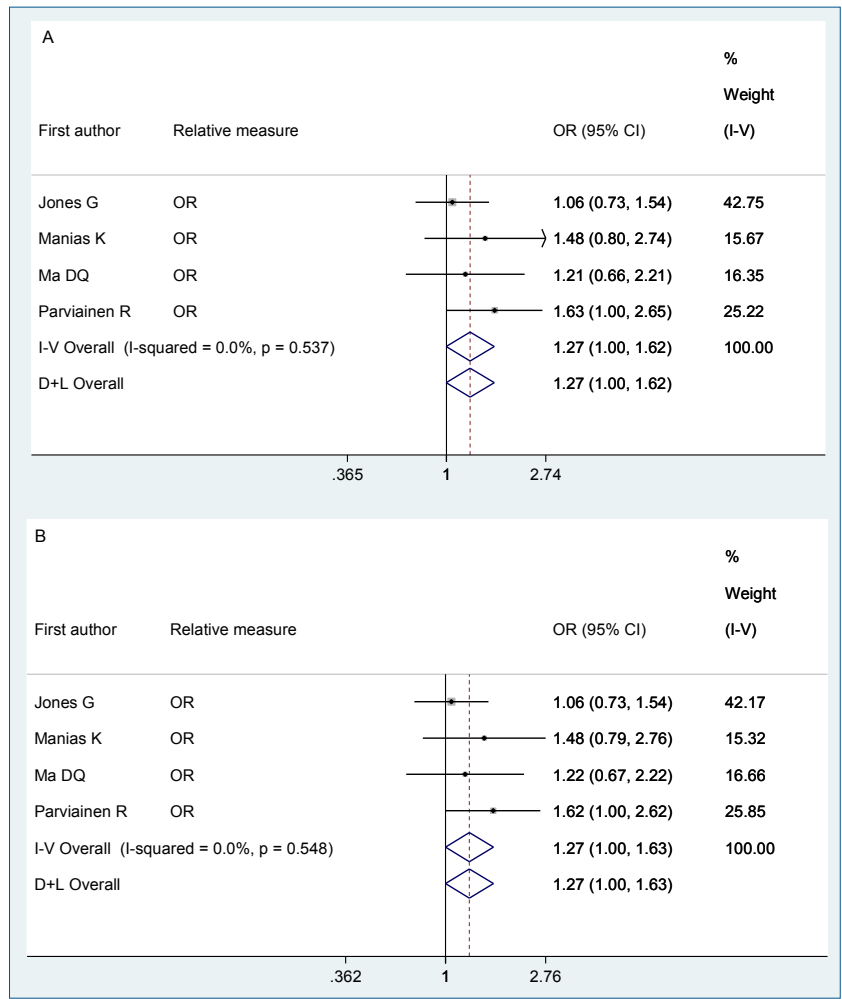

Fig. 4. Forest plot of 4 studies showing the crude effect of MSDP on the risk of bone fractures in offspring after the adjustment for MSDP misclassification through fixed-effect model: (A) deterministic sensitivity analysis; and (B) probabilistic sensitivity analysis. MSDP, maternal smoking during pregnancy; $\mathrm{Cl}$, confidence interval; $\mathrm{D}+\mathrm{L}$, DerSimonian and Laird; $I-V$, inverse variance; OR, odds ratio.

MSDP misclassification, the degrees of recall bias across the included studies were relatively different. Second, among the included studies, covariate adjustments were not performed in the same manner, and it seems that they did not attempt to adjust for all potential confounders. For example, in the study of Manias et al.,2) in addition to MSDP, fizzy drink intake, milk intake bone area, bone mineral content (BMC), bone mineral density (BMD), height, weight $z$ scores, physical activity, and diagnosis of asthma were included in the multivariate analyses. In the Parviainen et al. ${ }^{16)}$ study, sex, childhood rheumatism, asthma, body mass index, family's socioeconomic status, and maternal age were potential confounders. Third, the quality of the studies of the association between MSDP and bone fractures showed a high degree of heterogeneity.

The mechanism of the effect of maternal smoking on children's skeletal development is unclear. However, cigarette smoke contains thousands of harmful substances that can directly disrupt the formation of a growing skeleton. Evidence suggests that maternal smoking can reduce calcium absorption and cause placental dysfunction. Nutrient deficiency impairs fetal bone development. ${ }^{17,26,27)}$ In a prospective birth cohort study that aimed to evaluate the effect of parental smoking during pregnancy on the bone mass of 7,121 children at 10 years of age, maternal smoking was associated with an increased risk of total body less head, spine BMC, bone area, and BMD in girls; however, the relationship was not significant for boys. ${ }^{25)} \mathrm{A}$ 
large birth cohort study of 6,718 children in Northern Finland showed that MSDP was directly associated with an increased risk of in-hospital-treated fractures at pre-school age (RR, 1.83fold; 95\% CI, 1.06-3.02; $P=0.022$ ). This study also suggested an increased risk of bone fractures due to disordered fetal bone development as a result of maternal smoking. ${ }^{16)}$ Furthermore, in some studies, maternal smoking has been recognized as a limiting factor for fetal growth, ${ }^{28)}$ which can result in low birth weight, a risk factor for a lower BMC in childhood and adulthood.

A number of other potential mechanisms have been suggested for the harmful effect of MSDP, including impaired placental size and function, a low maternal blood sugar, maternal diet disorder, and low volume of breast milk. ${ }^{29-31)}$ Smoking has the greatest effect on placental function. Various studies have reported defects in placental function and size along with changes in endothelial function and epidermal growth factor in smoking mothers. ${ }^{32,33)}$ Jones et al. ${ }^{22)}$ reported a decrease in the placental weight of smoking mothers; after the adjustment for placental weight, the effect of smoking was not significant, which shows that this is an intermediate variable regarding the harmful effect of MSDP. Studies have suggested that different compounds in cigarettes can lead to impaired bone turnover. As a result, smoking causes the formation of bones that are prone to fractures. Clinically, these adverse effects are due to a significant loss of BMD related to smoking, which can vary depending on the degree of cigarette exposure. ${ }^{27}$

The study also had some strengths and limitations. First, to the best our knowledge, this is the first meta-analysis to investigate the association between MSDP and bone fracture in offspring. Second, most of the final studies included in the meta-analysis were cohort studies, the strongest observational study type, with high sample sizes and low risk of bias. And third, we handled misclassification bias using a Bayesian bias model to evaluate the effect of the potential MSDP misclassification on the findings. This study also has several limitations. First, a total of 5 studies were included in the meta-analysis, which makes it impossible to determine the true effect of publication bias on the results. Second, this study may be subject to some degree of selection bias due to missing potential studies.

In conclusion, the resulting associations from these observational studies should be interpreted with caution due to potential biases such as misclassification bias. After accounting for misclassification bias, this systematic review and meta-analysis demonstrated that MSDP may be associated with an increased risk of bone fractures among children whose mothers smoked during pregnancy. Therefore, primary prevention measures and health education programs should be designed and implemented to encourage women to stop smoking, especially during pregnancy.

\section{Conflicts of interest}

No potential conflict of interest relevant to this article was reported.
Supplementary materials

Supplementary materials $1-2$ can be found via https://doi. org/10.3345/cep.2019.01466.Supplement.

Supplementary material 1 . Search strategy. Supplementary material 2. Bayesian analysis.

See the commentary "Is correcting exposure misclassification bias an additional option in meta-analyses?" via https://doi.org/ 10.3345/cep.2020.00325.

\section{References}

1. Jones IE, Williams SM, Dow N, Goulding A. How many children remain fracture-free during growth? A longitudinal study of children and adolescents participating in the Dunedin Multidisciplinary Health and Development Study. Osteoporos Int 2002;13:990-5.

2. Manias K, McCabe D, Bishop N. Fractures and recurrent fractures in children; varying effects of environmental factors as well as bone size and mass. Bone 2006;39:652-7.

3. Anderson LN, Heong SW, Chen Y, Thorpe KE, Adeli K, Howard A, et al. Vitamin D and fracture risk in early childhood: a case-control study. Am J Epidemiol 2017;185:1255-62.

4. Baker R, Orton E, Tata LJ, Kendrick D. Risk factors for long-bone fractures in children up to 5 years of age: a nested case-control study. Arch Dis Child 2015;100:432-7.

5. Goulding A, Cannan R, Williams SM, Gold EJ, Taylor RW, Lewis-Barned NJ. Bone mineral density in girls with forearm fractures. J Bone Miner Res 1998;13:143-8.

6. Goulding A, Jones IE, Taylor RW, Manning PJ, Williams SM. More broken bones: a 4-year double cohort study of young girls with and without distal forearm fractures. J Bone Miner Res 2000;15:2011-8.

7. Lempesis V, Rosengren BE, Landin L, Tiderius CJ, Karlsson MK. Hand fracture epidemiology and etiology in children-time trends in Malmö, Sweden, during six decades. J Orthop Surg Res 2019;14:213.

8. Stenevi Lundgren S, Rosengren BE, Dencker M, Nilsson JÅ, Karlsson C, Karlsson MK. Low physical activity is related to clustering of risk factors for fracture-a 2-year prospective study in children. Osteoporos Int 2017; 28:3373-8

9. van den Heuvel EG, Steijns JM. Dairy products and bone health: how strong is the scientific evidence? Nutr Res Rev 2018;31:164-78.

10. Vanhelst J, Vidal F, Turck D, Drumez E, Djeddi D, Devouge E, et al. Physical activity is associated with improved bone health in children with inflammatory bowel disease. Clin Nutr 2019:S0261-5614(19)30300-0.

11. Cooper C, Eriksson JG, Forsén T, Osmond C, Tuomilehto J, Barker DJ. Maternal height, childhood growth and risk of hip fracture in later life: a longitudinal study. Osteoporos Int 2001;12:623-9.

12. Heppe DH, Medina-Gomez C, Hofman A, Rivadeneira F, Jaddoe VW. Does fetal smoke exposure affect childhood bone mass? The Generation R Study. Osteoporos Int 2015;26:1319-29.

13. Javaid MK, Crozier SR, Harvey NC, Gale CR, Dennison EM, Boucher $\mathrm{BJ}$, et al. Maternal vitamin D status during pregnancy and childhood bone mass at age 9 years: a longitudinal study. Lancet 2006;367:36-43.

14. Petersen SB, Olsen SF, Mølgaard C, Granström C, Cohen A, Vestergaard P, et al. Maternal vitamin D status and offspring bone fractures: prospective study over two decades in Aarhus City, Denmark. PLoS One 2014;9:e114334.

15. Rudäng R, Mellström D, Clark E, Ohlsson C, Lorentzon M. Advancing maternal age is associated with lower bone mineral density in young adult male offspring. Osteoporos Int 2012;23:475-82.

16. Parviainen R, Auvinen J, Pokka T, Serlo W, Sinikumpu JJ. Maternal smoking during pregnancy is associated with childhood bone fractures in offspring: a birth-cohort study of 6718 children. Bone 2017;101:202-5 .

17. Jones G, Hynes KL, Dwyer T. The association between breastfeeding, 
maternal smoking in utero, and birth weight with bone mass and fractures in adolescents: a 16-year longitudinal study. Osteoporos Int 2013;24: 1605-11.

18. Moher D, Liberati A, Tetzlaff J, Altman DG; PRISMA Group. Preferred reporting items for systematic reviews and meta-analyses: the PRISMA statement. PLoS Med 2009;6:e1000097.

19. Stang A. Critical evaluation of the Newcastle-Ottawa scale for the assessment of the quality of nonrandomized studies in meta-analyses. Eur J Epidemiol 2010;25:603-5.

20. Deeks JJ, Higgins JP, Altman DG. Analysing data and undertaking metaanalyses. In: Higgins HP, Green S, editors. Cochrane handbook for systematic reviews of interventions: Cochrane book series. The Cochrane Collaboration, 2008:243-96.

21. Higgins JP, Green S, edtors. Cochrane handbook for systematic reviews of interventions version 5.1.0 [Internet]. The Cochrane Collaboration; 2011 [updated 2011 Mar; cited 2020 Apr 10]. Available from: http:// www.handbook.cochrane.org.

22. Jones G, Riley M, Dwyer T. Maternal smoking during pregnancy, growth, and bone mass in prepubertal children. J Bone Miner Res 1999;14:14651.

23. Jones IE, Williams SM, Goulding A. Associations of birth weight and length, childhood size, and smoking with bone fractures during growth: evidence from a birth cohort study. Am J Epidemiol 2004;159:343-50.

24. Ma DQ, Jones G. Clinical risk factors but not bone density are associated with prevalent fractures in prepubertal children. J Paediatr Child Health 2002;38:497-500.

25. Macdonald-Wallis C, Tobias JH, Davey Smith G, Lawlor DA. Parental smoking during pregnancy and offspring bone mass at age 10 years: findings from a prospective birth cohort. Osteoporos Int 2011;22:180919.

26. Wong PK, Christie JJ, Wark JD. The effects of smoking on bone health.
Clin Sci (Lond) 2007;113:233-41.

27. Yan C, Avadhani NG, Iqbal J. The effects of smoke carcinogens on bone. Curr Osteoporos Rep 2011;9:202-9.

28. Jaddoe VW, Verburg BO, de Ridder MA, Hofman A, Mackenbach JP, Moll HA, et al. Maternal smoking and fetal growth characteristics in different periods of pregnancy: the generation R study. Am J Epidemiol 2007;165:1207-15.

29. Zhang ZY, Zeng JJ, Kjaergaard M, Guan N, Raun K, Nilsson C, et al. Effects of a maternal diet supplemented with chocolate and fructose beverage during gestation and lactation on rat dams and their offspring. Clin Exp Pharmacol Physiol 2011;38:613-22.

30. Trygg K, Lund-Larsen K, Sandstad B, Hoffman HJ, Jacobsen G, Bakketeig LS. Do pregnant smokers eat differently from pregnant non-smokers? Paediatr Perinat Epidemiol 1995;9:307-19.

31. Langhoff-Roos J, Wibell L, Gebre-Medhin M, Lindmark G. Effect of smoking on maternal glucose metabolism. Gynecol Obstet Invest 1993; 36:8-11.

32. Andersen MR, Walker LR, Stender S. Reduced endothelial nitric oxide synthase activity and concentration in fetal umbilical veins from maternal cigarette smokers. Am J Obstet Gynecol 2004;191:346-51.

33. Demir R, Demir AY, Yinanc M. Structural changes in placental barrier of smoking mother. A quantitative and ultrastructural study. Pathol Res Pract 1994;190:656-67.

How to cite this article: Ayubi E, Safiri S, Mansori K. Association between maternal smoking during pregnancy and risk of bone fractures in offspring: a systematic review and meta-analysis. Clin Exp Pediatr 2021;64:96-102. https://doi. org/10.3345/cep.2019.01466 